\title{
GREEN HOUSE AUTOMATION USING ANDROID APPLICATION
}

\author{
Prof Dhaval Tailor ${ }^{\# 1}$, Sejal Shah ${ }^{\# 2}$,Kunal Aswani ${ }^{\# 3}$ \\ ${ }^{\# 1}$ Department of Electrical Engineering, \\ A. D. Patel Institute of Technology, Vallabhvidhyanagar,India \\ \#2 Department of Electrical Engineering, \\ A. D. Patel Institute of Technology, Vallabhvidhyanagar,India \\ \#3 Department of Electrical Engineering, \\ A. D. Patel Institute of Technology, Vallabhvidhyanagar,India \\ ${ }^{1}$ tailordhaval@gmail.com \\ 2sejalshah4195@gmail.com \\ ${ }^{3}$ kunalaswani4849@gmail.com
}

\begin{abstract}
In recent past, the environment has played an adverse role in the life of humans as well as vegetation. More or less, the direct impact of this comes up on the economy of a country. Uneven weather condition leads to uncertain farming and also leads to cultivation damage. This has prerequisite to protect and cultivate the produce in a controlled environment along with automation. The very idea leads to the invention of greenhouse with automated features.A greenhouse is an enclosed system made up of special glass material which encloses vegetation grown inside it and thus provides protection from various hazards of environment. The green house traps the heat radiation from the sun and retains that heat inside the encloser. The project aims at automating the various parameters of green house such as temperature, moisture, humidity, ventilation, drip irrigation, security etc automatically. Whether to actuate a particular system or not depends on the desirable limits as set by the end user. Further, the entire control of the greenhouse could be done through an android application. The user sitting at distant place can control the temperature, water tank, drip irrigation, pesticides as and when desired through the application.
\end{abstract}

\section{INTRODUCTION}

This utility module relates to an automation of greenhouse leading to improved and efficient plant growth. A greenhouse enhances the capability of plant growth in a controlled environment. It is typically a type of framed construction having a roof which will permit some degree of penetration by the sun's rays.

The green house can be used to grow plants and vegetation in any part of the country irrespective of the climatic conditions. This yields to increase in the growth of endangered plants and thereby improves the economic crisis faced by the country. This also results in decrement in import duties and thus serves a larger purpose.

However maintaining the greenhouse in different seasons of the year is not an easy job. Removing weeds and algae in walkways, cleaning up dirt, turning on irrigation water at regular intervals, checking greenhouse cover regularly to ensure that there are no leaks and that no animals have crawled under it, keeping air moving into the greenhouse with a fan etc.

All this tasks leads to less viability of growing plants inside the green house. In order to solve above problems, an automation system is developed so as to control the parameters of the greenhouse through computerized system.

\section{LITERATURE REVIEW}

A. Open field cultivation Vs. Green house cultivation.

Conventionally, the people involved in the agriculture business cultivate their farming under the open arm of sun. But studies show that growing under the greenhouse conditions can enhance quality, quadruple production and enable growers to cultivate their crop for longer time.

One of the major advantages of greenhouse is the opportunity it gives to provide a variety of different produce in the "off season" creating greater availability for the customers. ${ }^{[3]}$ 


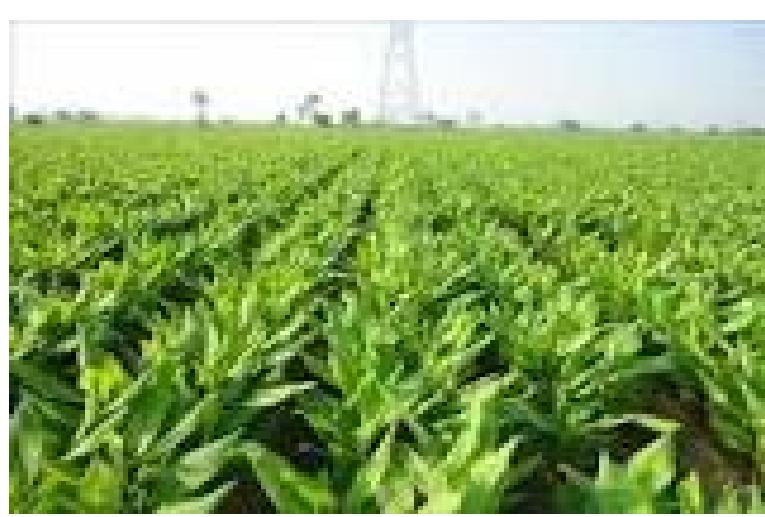

Fig1: Open field cultivation

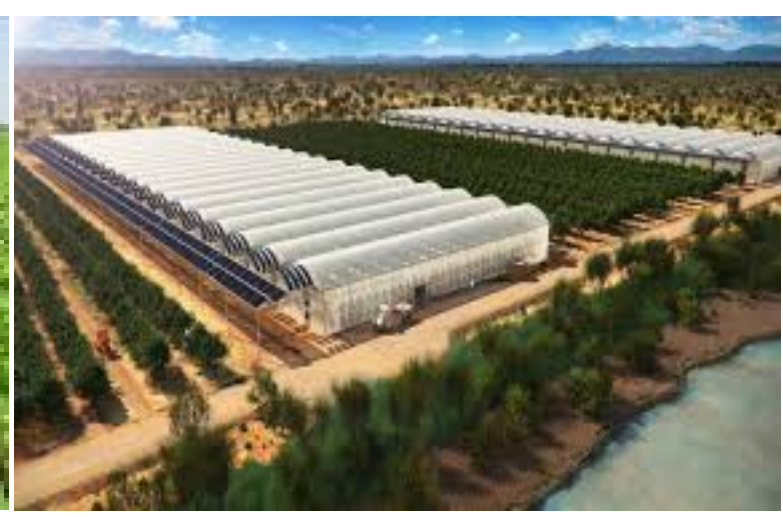

Fig 2: Greenhouse cultivation

B. Facts and Figures

TABLE I Crop Failure due to Various Reasons in Open Cultivation is Given Below

\begin{tabular}{|c|c|c|c|}
\hline Period & Area & Amount of destruction & Reason \\
\hline Nov 2016 & Karnataka & $\begin{array}{c}\text { Rabi crops coverage } 18.03 \text { lakh against target } \\
\text { of } 32.25 \text { lakh }\end{array}$ & $\begin{array}{l}\text { Poor southwest } \\
\text { monsoon. }\end{array}$ \\
\hline March 2015 & $\begin{array}{l}\text { Swathes of } \\
\text { North India }\end{array}$ & $50 \%$ of crops gets damaged & $\begin{array}{l}\text { Unseasonal } \\
\text { thundershowers and } \\
\text { hailstorms }^{[9]}\end{array}$ \\
\hline Nov 2015 & $\begin{array}{l}\text { Rajasthan, } \\
\text { Haryana, } \\
\text { UP, Punjab }\end{array}$ & $\begin{array}{l}\text { Farmers have so far sown only } 38.91 \text { lakh } \\
\text { hectares (lh) instead of } 46.87 \text { lakh }\end{array}$ & $\begin{array}{l}\text { Dry weather } \\
\text { extending to the post- } \\
\text { monsoon period }^{[10]}\end{array}$ \\
\hline Sep 2014 & North India & $\begin{array}{l}\text { By August 29, kharif crops were sown in } \\
\text { 966.25 lakh hectares. Last year, the figure was } \\
\text { 998.01 lakh hectares during the same period. }\end{array}$ & Lack of rain. ${ }^{[11]}$ \\
\hline
\end{tabular}

A study was conducted to determine the yield and quality of 'Dwarf Cavendish' banana, cultivated in open fields and also in protected (plastic greenhouse) cultivation. The site is located in the central south coastal region (altitude $50 \mathrm{~m}$, latitude $36^{\circ} 33^{\prime} \mathrm{N}$ ) of Turkey. Results obtained in all the qualitative and quantitative parameters clearly indicate that bananas grown in protected cultivation are superior to those grown in open-field cultivation, with a yield increase of $53 \%^{[1]}$. Similar results were obtained by Eckstein et al. (1998) and Galan Sauce et al. (1998). Eckstein al. (1998) stated that inside the greenhouse, plants were $34 \%$ taller and pseudo stem circumference was $4 \%$ greater at flowering stage compared with open field plants. ${ }^{[1]}$

\section{GREENHOUSE VS AUTOMATED GREENHOUSE}

An unautomated greenhouse proposes several difficulties in handling and maintaining the system. Moreover it also yields to increased man power. In order to have a coherent production, the florae needs continuous and timely water supply. The proper dose of the nutrients and pesticides yields to increased growth. And therefore in an unautomated greenhouse, personal monitoring is required to be the given to the cultivation.

However by automating the various parameters of the greenhouse, the above difficulties could by mitigated. Automation also brings in better accuracy, reduced man power and more reliable system.

This utility model mainly focuses on automating various factors of the greenhouse such timely supply of water, temperature control inside the greenhouse, moisture content in the soil, periodic sprinkling of the fertiliser and pesticides, system security etc. Furthermore, it also focuses on controlling the entire network through an android application. This facilitates the user to monitor and operate the system sitting at distant place. 
TABLEII. ComparisonBetween Open Field and Automated Green House

\begin{tabular}{|c|c|}
\hline Open Cultivation & Automated Green House \\
\hline Individual is required to water the plants. & $\begin{array}{c}\text { As per the requirement of plant, the automatic } \\
\text { watering to plant is given. }\end{array}$ \\
\hline Temperature is not controlled. & Temperature gets controlled automatically \\
\hline Labour cost is more. & Initial cost is much high. \\
\hline Plantation gets affected by animals. & Plantation does not get affected by animals. \\
\hline No Security to plantation. & Security to plantation is provided. \\
\hline On site presence is required & $\begin{array}{c}\text { Can be controlled and automated sitting at distant } \\
\text { place. }\end{array}$ \\
\hline Human labour increases & $\begin{array}{c}\text { Automation leads to less human efforts except a } \\
\text { technical expert. }\end{array}$ \\
\hline Quantity of plant cultivation is fine. & Quantity of plant cultivation is further increased. \\
\hline $\begin{array}{c}\text { Tomato growers had a mean income of KES } \\
188,591.67 .\end{array}$ & $\begin{array}{c}\text { Tomato growers had a mean income of KES } \\
345,920.83 .\end{array}$ \\
\hline
\end{tabular}

\section{SYSTEM BUILDING}

The system comprises of the an input unit, communication unit, control unit, detection unit, display unit and execution unit. The control unit is the main processing unit. It drives the execution unit as per the command given by the input unit. The detection unit consist of temperature sensor, water level sensor, moisture sensor, ir sensor and real time clock. The LCD displays the current status of the various system laid inside the house such as whether the drip irrigation system is on or off, whether the temperature in under prescribed limit or not. If not, then whether the cooling system is actuated or not etc.

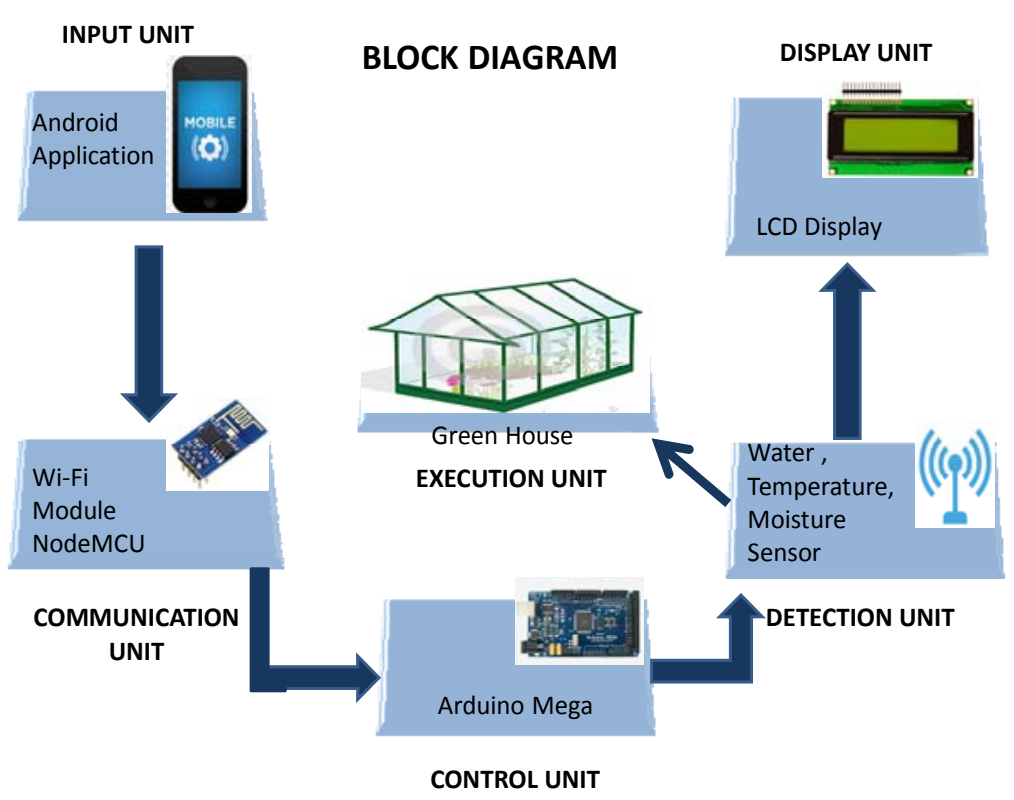

Fig 3.. Block Diagram of the system

The input is given by the user in the application installed in the cell phone. The command is then communicated to the controller through wifi module. The controller executes the command in the actual system. The data from the different sensor is monitored by the controller to determine the normal operating condition. This data which is fed back to the controller is then printed as a message inside the application. For example, if the temperature limit is violated, the cooling system gets activated. And hence, a message will be shown in the application about the activation of the cooling system.

Thus in the automatic control system, the growth environment in the shed can be detected in real time, moisture, other nutrients required by plants are supplied and controlled intelligently. 


\section{SYSTEM OPERATION THROUGH FLOWCHART}

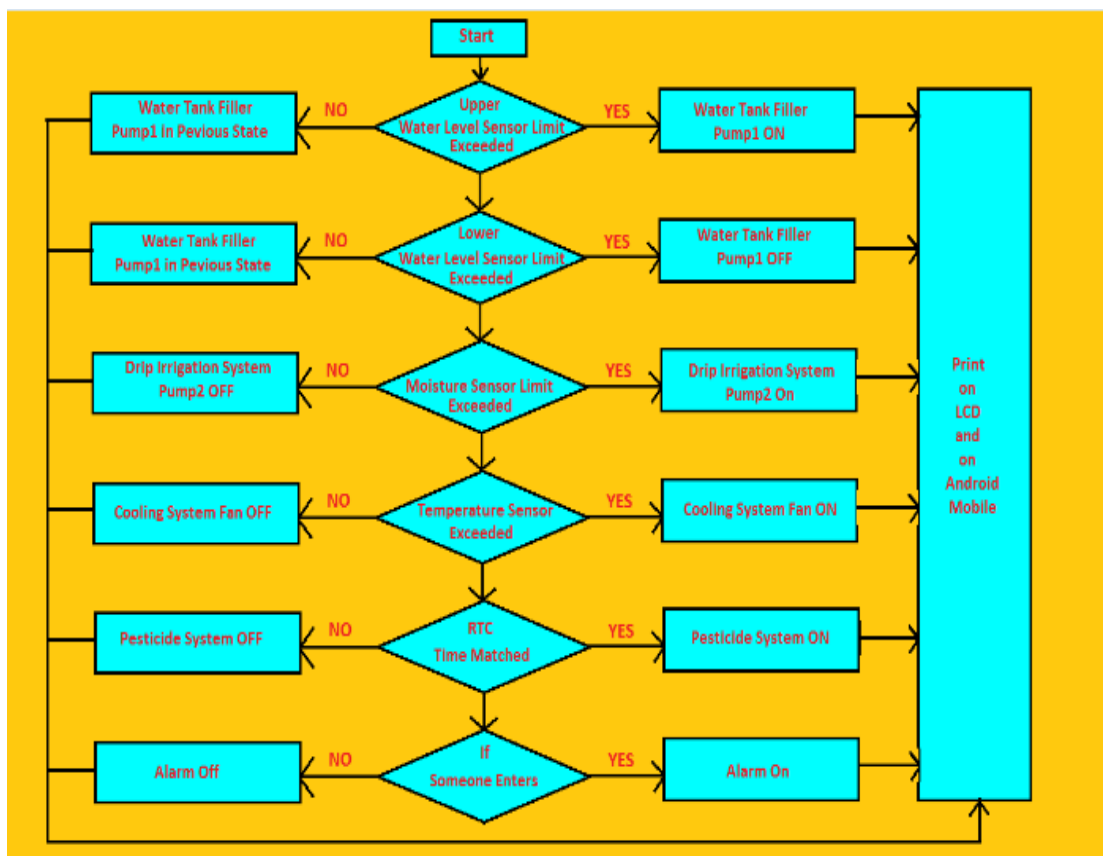

Fig 4.. Flowchart Review

1st module: Automatic Water Tank Filler

Two water level sensors are incorporated in the main tank. The sensor senses the extremities of tank. The upper sensor turns off the water intake from the reservoir when tank is filled up and the lower sensor turn on water intake when the water levels are too down. Also the status of pump is displayed on LCD and on android mobile.

2nd module: Automatic Drip Irrigation System

Moisture level sensor is used to check the moisture content in the soil ${ }^{[2]}$. Whenever the Moisture content in soil gets lower, the drip irrigation system gets turn on and water is supplied in the field. When moisture content goes high (as set by the end user), the irrigation system is turned off. Thus in this way Automatic watering to the plant as per requirement is given. Also its status is displayed on LCD as well on Android Mobile.

3rd Module: Automatic Pesticide Sprinkling

At beginning the soil is tested and for its better growth the types of pesticide and the amount in which is should be sprinkled is decided. Based on this, a particular time is decided in which pesticide are sprinkled for particular period. This is monitored by a real time clock(RTC). It actuated the sprinkling mechanism for a definite time as suggested by the user.

4th Module: Automatic cooling system

Every plant grows under certain temperature conditions. An agronomist decides this criteria which is then maintained inside the greenhouse for the efficient growth of plants. For this the temperature sensor is used ${ }^{[2]}$. If temperature goes beyond some limit which is not suitable for plants then the cooling system (Fan) gets turned on and the internal heat in the greenhouse is extracted out. Thus maintaining a suitable temperature in greenhouse. 
TABLE III. List of Sensors Used.

\begin{tabular}{|c|c|}
\hline Specification \\
\hline K-0135 \\
Operating voltage: DC5V \\
Working current : less than 20mA \\
Sensor Type : Analog \\
Working Temperature: $10-30 \mathrm{C}$ \\
Power supply: DC 3.5 5.5V \\
Supply Current: measurement $0.3 \mathrm{~mA}$ \\
standby $60 \mu \mathrm{A}$ \\
Sampling period: more than $2 \mathrm{~seconds}$ \\
\\
Operating Voltage: 3.3 to $5 \mathrm{~V}$ dc \\
Working Current: 0 to $35 \mathrm{~mA}$ \\
Sensor in dry soil $0 \sim 300$ \\
Sensor in humid soil $300 \sim 700$ \\
Sensor in water $700 \sim 950$
\end{tabular}

5th Module: Security of Greenhouse

Security is a vital part. The user do not wish to appreciate unnecessary intervene of unwanted figures. So to prevent this, a proximity sensor is used which buzzes an alarm and a displays a message on LCD and applucation. This way the security aspects are taken care of.

6th Module: Lighting System

To make the greenhouse attractive and to promote it, the glorious illumination system is adopted. At night for vision as light is necessary so LDR is used and as per necessary the illumination is lit up. ${ }^{[4]}$

7th Module: Android mobile application

It is "The heart" of the project. For better reliability, making system more effective and user friendly, Android Mobile application is made. Each and Every parameters of greenhouse is analysed and can be controlled through this app. We have used Wifi module for it ${ }^{[4]}$. This enables a user to operate and monitor the system sitting at distant place.
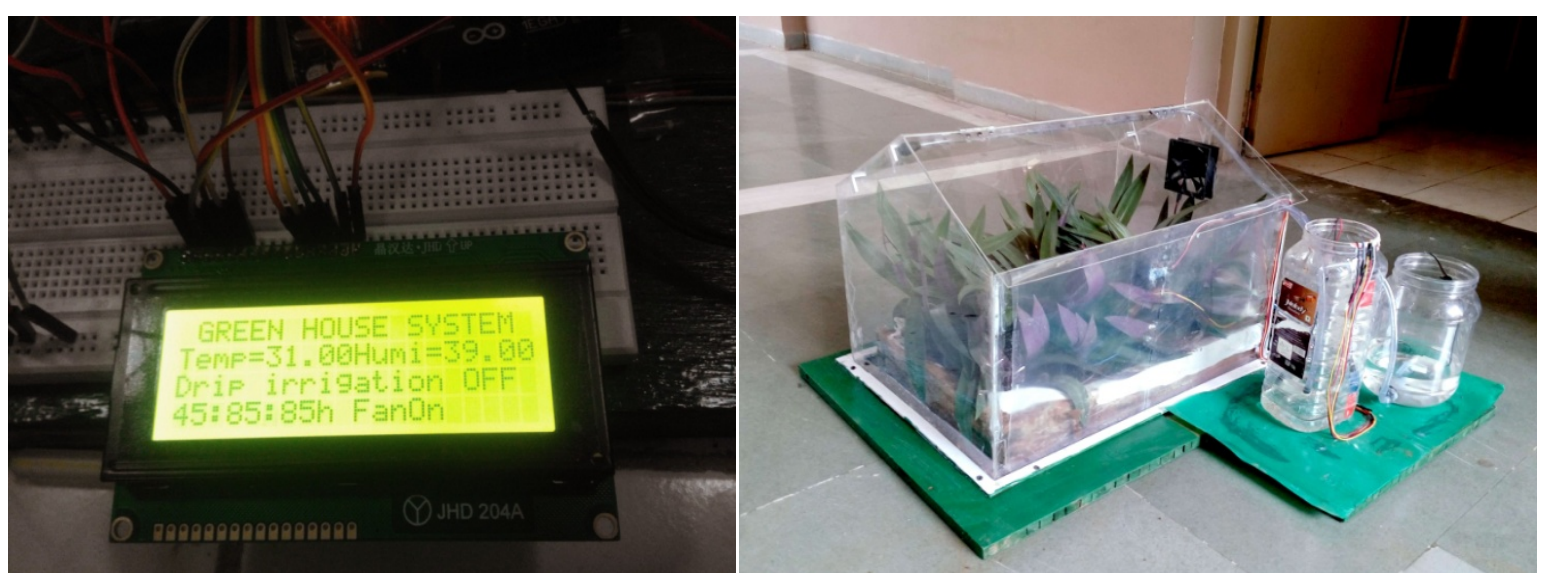

Fig 5. Model GreenhouseFig 6. LCD display

\section{CONCLUSION}

Greenhouse Automation is an area which has a wide scope of growth. Automation is one such area enabling the user to have more reliable, accurate and economical system on a longer span of time. This utility model emphasis on automating each and every parameter inside the greenhouse. The present day industries focus more on modernisation and customer satisfaction. And larger part of India's economy is dedicated to the agriculture business. So more or less, this model comes morehandy and serves a larger purpose to the industry as a whole. 


\section{REFERENCES}

[1] H. Gubbuk \& M. Pekmezci "Comparison of open-field and protected cultivation of banana (Musa spp. AAA) in the coastal area of Turkey"

[2] LIU Wei ZHANG Da - yin ZHANG Xi WANG Zhi - gang QIN Zhan - yong LUO Chun - lei MA Yan -min "Greenhouse system and intelligent greenhouse control system".

[3] GeorgeMbakahya: standardmedia.co.ke/business/article/2000200973/greenhouse-vs-open-field

[4] Hu Jiang Hu Wei Bao Pingjun "Fully automated greenhouse control system"

[5] https://en.wikipedia.org/wiki/March_2015_North_India_unseasonal_rain

[6] http://food.ndtv.com/food-drinks/kharif-crop-in-over-35-lakh-hectare-hit-due-to-rain-failure-1630511

[7] Comparative Analysis of Greenhouse VS Open-flied smallscale Tomato production in Nakuru-North district, Kenya by WACHIRA JOHN MWANGI.

[8] http://www.thehindu.com/news/cities/bangalore/Double-whammy-for-farmers-as-northeast-monsoon- fails/article16443396.ece

[9] http://timesofindia.indiatimes.com/india/Heavy-rain-hailstorms-destroy-crops-in-north-India/articleshow/46591081.cms

[10] http://indianexpress.com/article/india/india-news-india/farmers-face-fourth-failure-dry-spell-hits-dal-wheat-crop/

[11] http://www.indiawaterportal.org/articles/monsoon-delivers-hard-blow-farmers

\section{AUTHOR PROFILE}

Prof. Dhaval N Tailor working as an Assistant Professor in Electrical Engineering Department, A. D. Patel Institute of Technology, New V V Nagar, India.

Sejal Shah is pursuing B.E.Electrical Engineering Department, A. D. Patel Institute of Technology, New V V Nagar, India.

Kunal Aswani is pursuing B.E.Electrical Engineering Department, A. D. Patel Institute of Technology, New V V Nagar, India 